\title{
Perancangan dan Pembuatan Visualisasi Data Dana Penelitian Internal dan Hibah Dikti LPPM Universitas Multimedia Nusantara
}

\author{
Wenni Indriani Loka ${ }^{1}$, Friska Natalia ${ }^{2}$ \\ Program Studi Sistem Informasi, Universitas Multimedia Nusantara, Tangerang Selatan, Indonesia \\ wenni.indriani@student.umn.ac.id \\ friska.natalia@umn.ac.id
}

Diterima 24 Januari 2019

Disetujui 24 Juni 2019

\begin{abstract}
Universitas Multimedia Nusantara is one of the private universities that has a division of the Institute for Research and Community Service or called LPPM. LPPM Division is in charge of arranging licensing conducted in the university environment, whether conducted by lecturers and students. To be able to issue licenses, especially those related to funds, LPPM should look at the existing track record so that the permits issued are not available funds and the funds to be budgeted will be sufficient for the needs of the research fund to be conducted next in the period. Therefore, the role of Business Analyst in the LPPM division is required to visualize the data used, ie research, conduct various studies undertaken by the study program within a certain period, complete funds, and other details such as research title, research category, and name or conduct research others. Research. Data visualization will facilitate LPPM in monitoring existing research and become a useful tool in research licensing decisions.
\end{abstract}

Index Terms- big data, business analyst, data visualization

\section{PENDAHULUAN}

Lembaga Penelitian dan Pengabdian Masyarakat Universitas Multimedia Nusantara (LPPM UMN) berfungsi sebagai koordinator kegiatan penelitian dan pengabdian masyarakat antara program-program studi yang ada di Universitas Multimedia Nusantara dengan masyarakat. Para staf pengajar maupun mahasiswa yang ingin mengajukan penelitian dalam lingkup UMN harus mengajukan proposal terlebih dahulu ke divisi LPPM. Dana yang diajukan untuk melakukan penelitian tercantum di dalam proposal yang diajukan. Penelitian yang dilakukan terdiri dari beberapa jenis dan akan terus dilakukan oleh seluruh program studi secara periodik. Informasi mengenai program studi yang melakukan penelitian, dana yang dibutuhkan tiap program studi, banyaknya penelitian yang dilakukan, dan data-data lainnya akan disimpan sebagai arsip dan sebagai acuan untuk menentukan besaran dana yang dibutuhkan untuk periode berikutnya.

Program studi UMN yang terus bertambah dan waktu yang terus berjalan membuat data yang terus- menerus bertambah dan mempersulit pengelolaan data yang dapat memicu human error. ${ }^{[12]}$ Banyaknya data yang ada dan meningkatnya kompleksitas membuat proses pengolahan dan pencarian informasi tertentu membutuhkan waktu yang cenderung lama karena sulitnya melakukan pencarian. ${ }^{[12]}$ Hal inilah yang melatarbelakangi pembuatan visualisasi data. Data yang ada diteliti secara manual dengan menggunakan Microsoft Excel. Keterbatasan fitur yang dimiliki Microsoft Excel dan bertambahnya data menyebabkan proses pemahaman informasi yang tersedia semakin sulit dan membutuhkan waktu yang relatif lama.

Pembuatan visualisasi data menggunakan aplikasi Business Inteligence, yaitu Microsoft Power BI yang dapat mengelompokkan dana penelitian internal maupun hibah Dikti berdasarkan tanggal pelaksanaan, program studi, maupun status dari penelitian tersebut. Detail dari penelitian juga dapat diketahui dengan cepat dan mudah tanpa perhitungan manual.

Hasil dari visualisasi data diharapkan dapat menjadi solusi dari permasalahan yang ada. Dengan adanya visualisasi data, informasi yang tersedia dapat dipahami dengan cepat karena menggunakan grafik dan tabel yang responsif serta warna-warna yang mendukung. Hal ini akan menghemat waktu dan tenaga dalam pengolahan data serta memperkecil kemungkinan human error karena hampir seluruh perhitungan dilakukan oleh software.

\section{LANDASAN TEORI}

\section{a) Sifat Big Data}

Big data memiliki 2 sifat yang bersifat khusus, yaitu data terstruktur, semi terstruktur, atau tidak terstruktur, misalnya, data dalam basis data relasional, diskusi papan buletin, dan video di website masing-masing; sifat lainnya adalah data yang bersifat internal atau eksternal organisasi, misalnya, pesan ke purna jual layanan di satu tangan. Big data yang dikelola dengan baik akan dapat membantu pekerjaan ke arah yang lebih baik. ${ }^{[4]}$ 
b) Tipe Big Data

Big data memiliki beberapa tipe yang dapat dikenali: ${ }^{11][2]}$

- $\quad$ "Baris dan kolom" dari tabel dan database yang relasional.

- teks

- gambar

- time-series

- $\quad$ space-related data, misalnya mengenai jalan dan wilayah kekuasaan hukum

- space-time positions, seperti tempat keberadaan individu pada saat tertentu

- Network data, pada dasarnya data tentang hubungan antara pasangan elemen dalam suatu populasi

- dan jenis-jenis data lainnya yang dapat berupa kombinasi dari jenis data yang telah dikenali.

\section{c) Pengertian Big Data}

Business Intelligent (BI) merupakan solusi untuk mengatasi permasalahan big data, baik untuk termasuk untuk bisnis yang berskala kecil dan medium. BI adalah kemampuan dalam bidang teknologi untuk mengumpulkan, menyimpan, menganalisis, dan menyediakan akses ke data untuk membantu pengguna perusahaan membuat keputusan bisnis yang lebih baik yang mencakup kegiatan sistem pendukung keputusan, permintaan dan pelaporan, pemrosesan analitik online $(O L A F)$ analisis statistik, peramalan, dan penambangan data. ${ }^{[3]}$ Business Intelligent adalah fondasi dimana kinerja sistem manajemen tumbuh dan berkembang untuk dapat memperoleh nilai manfaat yang tersimpan dalam data. Data mining dan predictive analysis yang dilakukan dengan baik dapat memberikan wawasan baru yang berdampak pada keunggulan kompetitif dalam bisnis yang sedang dijalankan. ${ }^{[5][6]}$ Hasil dari data mining dan predictive analysis dapat dilihat di dashboard. Dashboard memiliki kapasitas untuk menyediakan informasi penting dan tepat waktu bagi user untuk digunakan dalam pengambilan keputusan. Dashboard menyajikan data dalam cara yang relevan, ringkas, dan terencana serta memiliki infrastruktur pendukung yang mampu memperbarui dashboard dalam waktu yang tepat. $[7]$

Microsoft Power BI merupakan salah satu tools yang dalam bidang Business Intelligent yang dapat digunakan untuk melakukan data mining dan predictive analysis. Pemanfaatan visualisasi data menggunakan Microsoft Power BI untuk keperluan bisnis dan organisasi sebelumnya telah dilakukan, salah satunya untuk meningkatkan mutu pelayanan pada rumah sakit Semen Padang Hospital. ${ }^{[10]}$

\section{TAHAP PENGERJAAN}

Pengerjaan visualisasi menggunakan metode CRISP DM yang meliputi tahap business understanding, data understanding, data preparation, modelling, evaluation, dan deployment. ${ }^{[1]}$ Berikut ini merupakan fase yang dilalui untuk menyelesaikan pembuatan visualisasi data dana anggaran penelitian LPPM universitas:

\section{a) Business understanding}

Pembuatan visualisasi data diawali dengan mengumpulkan seluruh data yang diperlukan. Jenis dan banyak data yang dibutuhkan bergantung pada kebutuhan visualisasi.

\section{b) Data understanding}

Data yang diterima dapat memiliki format yang berbeda-beda. Pada tahapan ini data mengalami transformation, format yang dimiliki data akan diubah menjadi format tertentu yang telah disetujui sebelumnya. Perubahan format data hanya dilakukan apabila format data yang tersedia berbeda dengan format data yang dibutuhkan. Selain itu data yang diterima harus memiliki satu format yang konsisten pada tiap kolomnya. Cleansing data dilakukan untuk menyamakan isi kolom dengan format yang ditentukan sebelumnya.

\section{Data Preparation}

Database dibuat untuk menjadi sumber data visualisasi. Jenis dan lokasi database yang dibuat disesuaikan dengan keperluan dan kondisi dari organisasi atau badan yang membutuhkan. Pada tahap ini juga dilakukan. Bila data yang ada sudah bersih, maka pembuatan dashboard dapat dilakukan. Jenis diagram yang digunakan akan menyesuaikan dengan kebutuhan organisasi atau badan yang membutuhkan. Bila perlu, akan dilakukan perhitungan dengan rumus khusus untuk dapat memvisualisasikan hal tertentu.

\section{d) Modelling}

Database yang sudah dibuat harus dapat tersambung dengan tools yang akan digunakan untuk membuat visualisasi. Koneksi dapat dilakukan dengan mengunduh connector tertentu ataupun tanpa bantuan connector, sesuai dengan tools dan database yang digunakan.

\section{e) Evaluation}

Pada tahap evaluasi, dashboard yang telah selesai dibuat akan dilihat kesesuaiannya dengan kebutuhan awal. Tahap evaluasi dinyatakan berhasil apabila hasil dashboard telah memenuhi tujuan awal dibuat. 


\section{f) Deployment}

Bila data yang ada sudah bersih, maka pembuatan dashboard dapat dilakukan. Jenis diagram yang digunakan akan menyesuaikan dengan kebutuhan organisasi atau badan yang membutuhkan. Bila perlu, akan dilakukan perhitungan dengan rumus khusus untuk dapat memvisualisasikan hal tertentu.

\section{PEMbuatan Visualisas}

a) Pengerjaan dimulai dengan mengumpulkan data yang dibutuhkan untuk membuat visualisasi. Data disusun oleh admin LPPM yang bertugas menggunakan Microsoft Excel.

b) Tahap berikutnya adalah mengubah format xlsx. yang merupakan default format dari Microsoft Excel menjadi CSV. Hal ini dilakukan agar proses load data menjadi lebih cepat karena format CSV lebih ringan daripada format xlsx.

c) Database yang digunakan adalah MySQL. Peran XAMPP diperlukan dalam terhubung dengan database MySQL. Setelah terhubung, dibuat 3 database dalam localhost untuk menjadi data source dari visualisasi data yang dibuat. Database yang dibuat adalah; ' $C F P$ ' untuk data penelitian Call For Paper, 'Rekap' untuk data rekapitulasi penelitian internal dosen universitas, dan 'Hibah' untuk data penelitian hibah dikti. Berdasarkan data yang diterima, Call For Paper memiliki penelitian yang dimulai sejak tahun 2012 dan memiliki data yang berkelanjutan hingga tahun 2017, yang berarti tersedia data penelitian antara tahun 2012 dan 2017. Data yang tersedia untuk rekapitulasi penelitian dosen universitas serta penelitian hibah dikti tersedia dari tahun 2015 hingga 2017. Ketiga database dibuat dengan nama yang berbeda sesuai dengan jenis penelitian untuk mengurangi kemungkinan kesalahan saat menentukan datasource. Seluruh file CSV dibuat berdasarkan tahun penelitian dilaksanakan. Pemisahan database juga dilakukan untuk mempermudah admin yang memiliki tugas untuk memperbarui data di masa depan.

d) Koneksi antar Microsoft Power BI dengan MySQL database dilakukan setelah database selesai dibuat. Koneksi dapat dilakukan dengan menggunakan MySQL Connector yang dapat diunduh di website resminya secara gratis. Versi yang digunakan adalah MySQL Connector Net 6.10.6. e) Cleansing dilakukan setelah Microsoft Power BI sudah terhubung dengan database MySQL. Judul dari setiap kolom dibuat sama persis baik dari karakter huruf dan tanda baca, huruf kapital, dan spasi yang digunakan. Berikut ini merupakan judul tabel Call For Paper yang digunakan sebagai datasource Microsoft Power BI:

- No

- Peserta

- Authors

- Prodi

- Kategori

- Judul Acara/Penyelenggara/Tempat Acara/Judul Paper/Karya Ilmiah/Project Penelitian

- Tanggal Mulai Pelaksanaan

- Tanggal Selesai Pelaksanaan

- Perkiraan Biaya

- Realisasi Biaya

- Proceeding

Judul tabel yang digunakan sebagai datasource rekapitulasi penelitian dosen adalah sebagai berikut:

- No.

- No. Kontrak

- Peneliti

- Judul Penelitian

- Fakultas

- Program Studi

- Jumlah Dana

- Laporan Penelitian

- Monev I

- Monev II

Sedangkan judul dari tabel yang digunakan untuk visualisasi dana hibah dikti adalah seperti berikut:

- No.

- Semester

- Tahun

- Ketua Peneliti

- NIDN Ketua

- Program Studi Anggota 1

- NIDN Anggota 1

- Program Studi Anggota 2

- NIDN Anggota 2

- Program Studi

- Judul Hibah dan Kemenristekdikti

Proses lain yang dilakukan adalah menghilangkan simbol dan karakter lainnya yang dianggap tidak terpakai dan hanya mengganggu dalam proses visualisasi. Proses ini paling banyak digunakan pada saat 
menangani kolom yang berhubungan dengan nominal uang. Selain pada kolom tersebut, proses penghilangan spasi berlebih yang tidak pada tempatnya juga dilakukan agak tidak terjadi redudansi terhadap jumlah keanekaragaman data yang ada. Redudansi beresiko dapat mempengaruhi tingkat akurasi hasil visualisasi.

f) Selanjutnya seluruh isi tabel digabungkan dengan menggunakan fitur Append sesuai dengan jenis penelitian untuk membentuk satu tabel induk yang akan digunakan sebagai tabel utama dalam membuat dashboard. Kolom tahun pada Call For Paper dan Rekapitulasi Penelitian Dosen dibuat secara mandiri. Terdapat total 5 dashboard yang dibuat. Gambar 1 menunjukkan dashboard untuk anggaran dana Call For Paper:

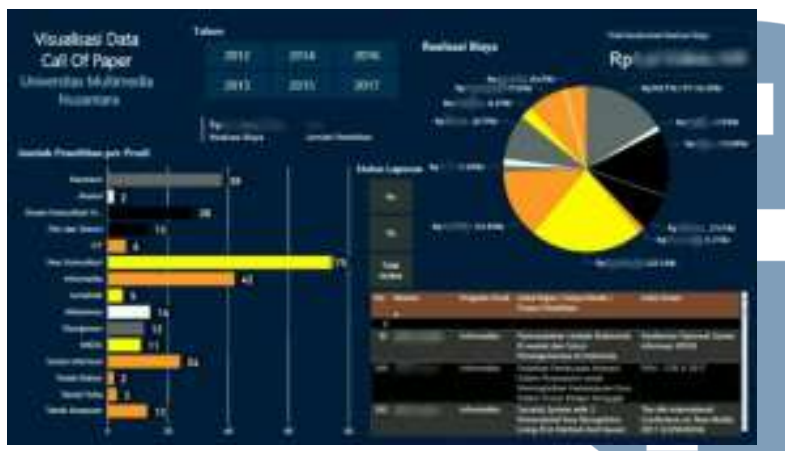

Gambar 1. Dashboard Call For Paper

Komponen diagram dan jenis visualisasi yang digunakan dalam dashboard call for paper adalah sebagai berikut:

- $\quad$ Slicer

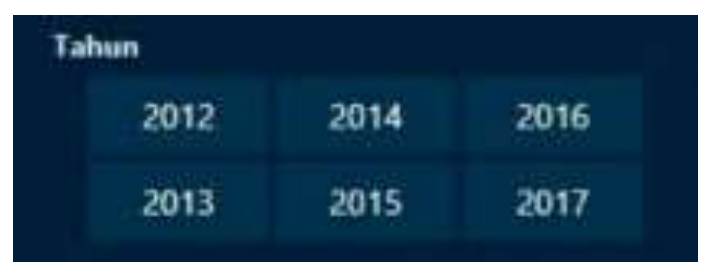

Gambar 2. Slicer dalam Dashboard Call For Paper

Jenis visualisasi ini digunakan sebagai opsi untuk melihat visualisasi berdasarkan tahun dan status laporan sesuai yang diinginkan. Field yang diambil adalah kolom Year dan Proceeding yang berasal dari tabel gabungan dari seluruh tahun.
- Multi-row Card

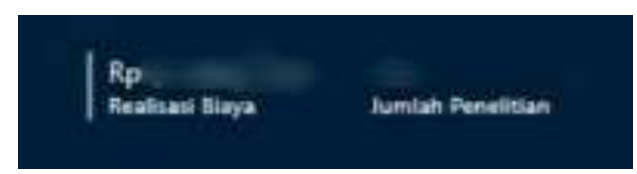

Gambar 3. Multi-row Card dalam Dashboard Call For Paper

Jumlah realisasi biaya dan jumlah penelitian yang dilakukan dapat dilihat dalam visualisasi jenis Multirow Card. Kolom yang digunakan sebagai sumber visualisasi adalah kolom realisasi biaya dan jumlah penelitian. Jumlah penelitian dibuat dengan menggunakan fungsi measure untuk mendapatkan hasil seluruh jumlah penelitian dari program studi tertentu. Rumus measure yang digunakan adalah sebagai berikut:

\section{Jumlah Penelitian}

$=\operatorname{COUNT}($ CFPall $[$ Program Studi $])$

- Staked-Bar Chart

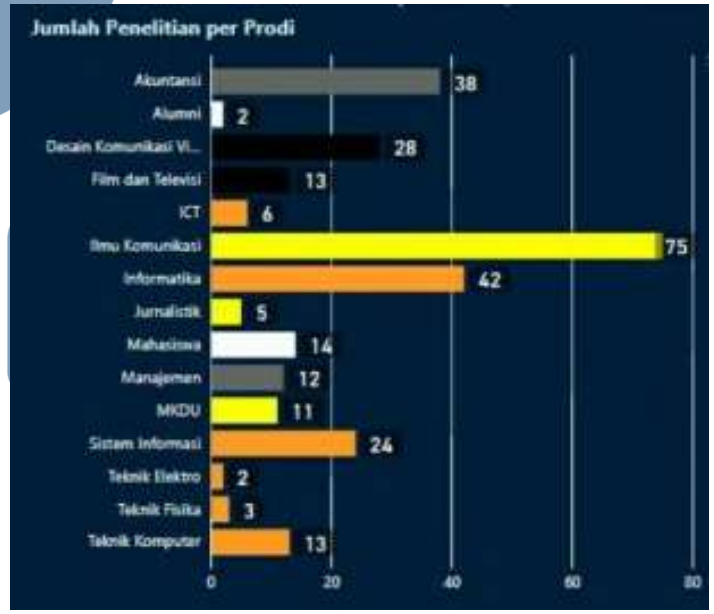

Gambar 4. Staked-Bar Chart dalam Dashboard Call For Paper

Stacked-bar Chart digunakan untuk memvisualisasikan jumlah dari penelitian yang dilakukan di dalam universitas yang telah disusun berdasarkan program studi. Angka yang terdapat pada bagian akhir merupakan jumlah penelitian. Kolom yang digunakan sebagai sumber visualisasi adalah Program Studi. Warna yang digunakan untuk mewakili tiap program studi sama 
dengan warna yang fakultas yang bersangkutan.

- Pie chart

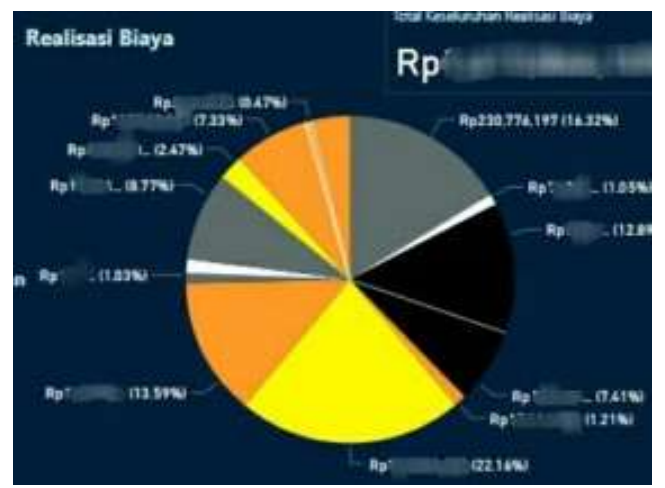

Gambar 5. Pie Chart dalam Dashboard Call For Paper

Diagram pie menunjukkan dana yang dianggarkan untuk menjalankan penelitian Call For Paper. Kolom yang menjadi sumber dari diagram ini adalah kolom program studi, kolom realisasi biaya, dan kolom jumlah penelitian. Kolom jumlah penelitian yang digunakan memakai fungsi measure yang juga dipakai dalam visualisasi Multi-row Chart.

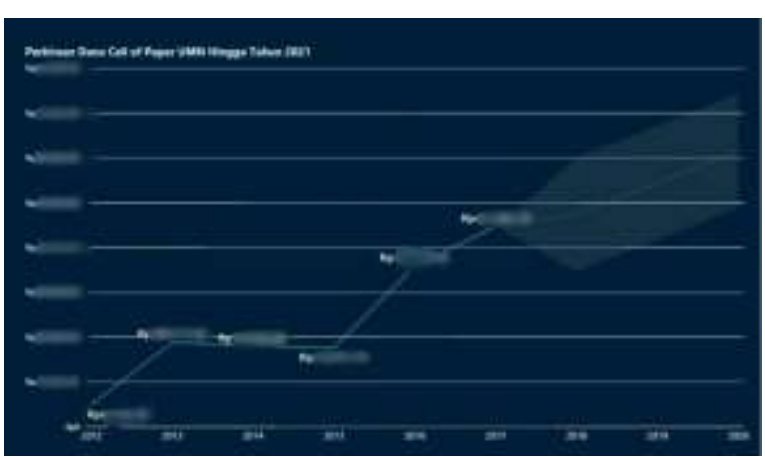

Gambar 7. Forecast Call For Paper

Dashboard lain yang dibuat adalah mengenai Rekapitulasi Penelitian Dosen. Jenis visualisasi yang digunakan pada dashboard tersebut adalah sebagai berikut:

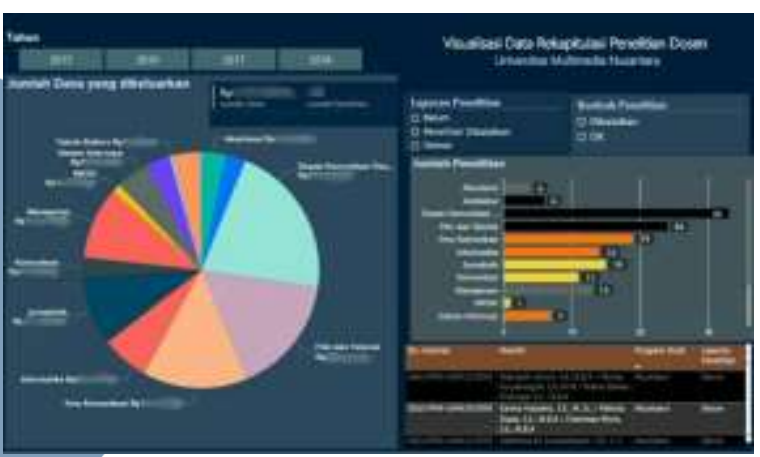

Gambar 8. Dashboard Rekapitulasi Penelitian Dosen

Jenis dari visualisasi yang menjadi bagian dari

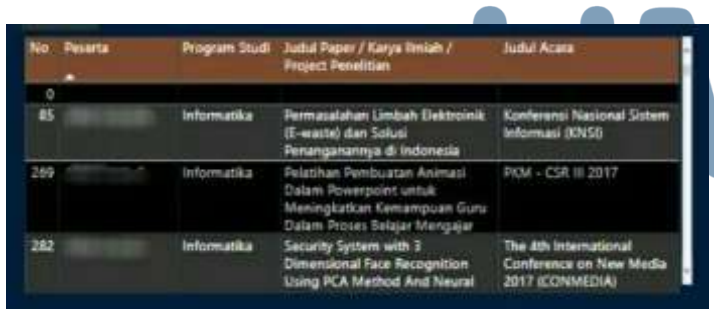

Gambar 6. Table dalam Dashboard Call For Paper

Informasi yang tersedia pada Table adalah nomor, peserta, program studi, judul paper, dan judul acara. Kolom yang digunakan sebagai sumber visualisasi adalah kolom yang sama dengan kolom pada tabel.

Dashboard ini memiliki satu jenis visualisasi yang menyediakan visualisasi mengenai anggaran dana untuk penelitian yang sudah berjalan serta melakukan Forecast terhadap dana anggaran yang akan dikeluarkan. Forecast dibuat hingga tahun 2021 dengan menggunakan diagram jenis line chart. dashboard rekapitulasi penelitian dosen adalah:

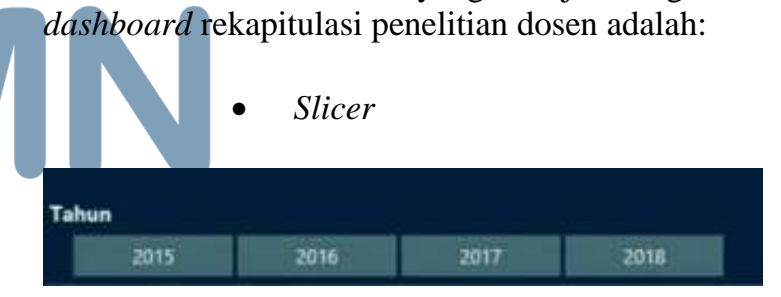

Gambar 3. Slicer dalam Dashboard Call For Paper

Slicer digunakan untuk membatasi visualisasi yang ditampilkan berdasarkan opsi tahun penelitian berjalan, status laporan penelitian, dan status kontrak penelitian. 
- Pie chart

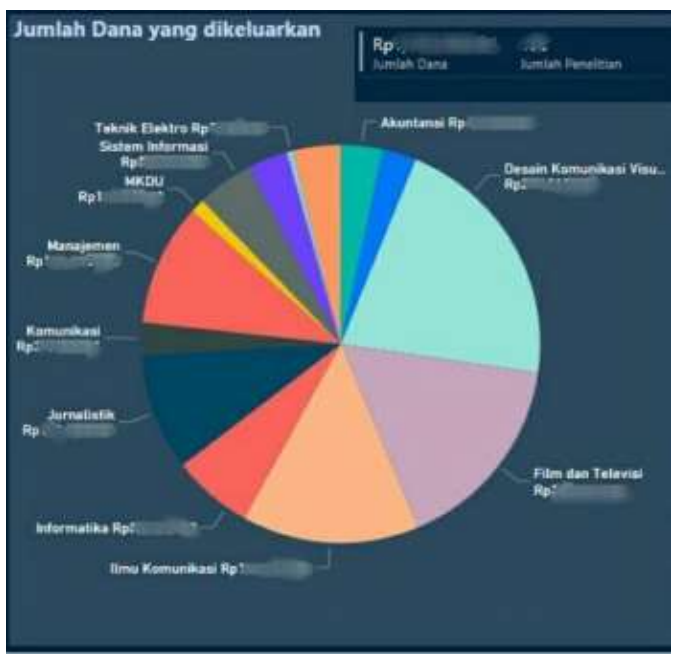

Gambar 10. Pie Chart dalam Dashboard Call For Paper

Visualisasi jenis ini digunakan untuk melihat anggaran dana yang digunakan oleh program studi tertentu. Kolom yang menjadi dasar visualisasi adalah kolom jumlah dana, program studi, dan tahun.

- Multi-row Chart

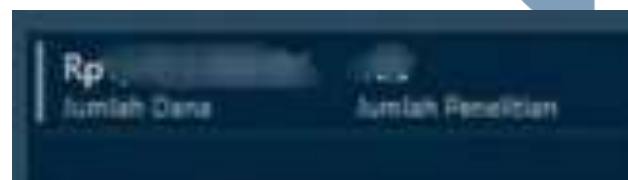

Gambar 11. Multi-row Card dalam Dashboard Call For Paper

Informasi yang disediakan oleh multirow card adalah jumlah dana yang dianggarkan untuk penelitian beserta jumlah penelitian yang dilakukan dalam oleh program studi dalam periode tertentu. Jumlah dana dan jumlah penelitian merupakan sumber data visualisasi jenis ini. Jumlah penelitian di dapat melalui measure yang menggunakan rumus yang sama dengan jenis visualisasi multi-row chart pada penelitian call for paper.
- $\quad$ Stacked-bar Chart

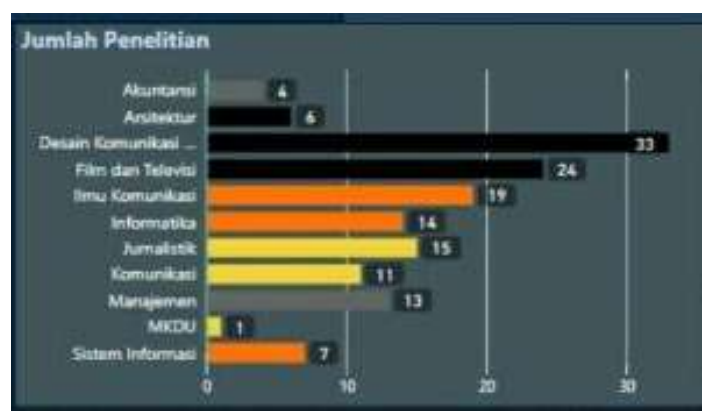

Gambar 12. Stacked-bar Chart dalam Dashboard Call For Paper

Jumlah penelitian yang dilakukan oleh program studi dapat dilihat dalam stacked-bar chart. kolom yang digunakan adalah program studi dan perhitungan khusus pada kolom tahun.

\section{- Table}

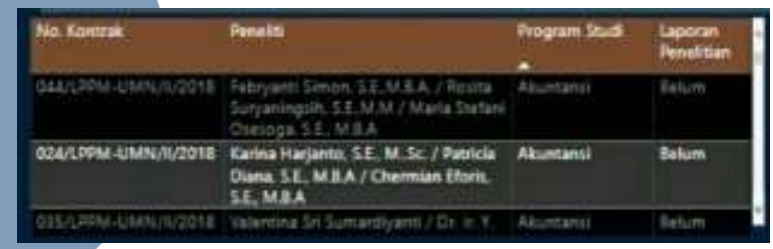

Gambar 13. Table dalam Dashboard Call For Paper

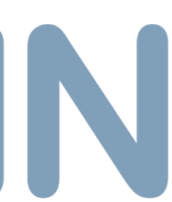

Informasi mengenai nomor kontrak, peneliti, program studi, dan status laporan penelitian tercantum pada visualisasi data jenis Table. Kolom yang digunakan sebagai sumber data merupakan kolom yang sama dengan judul kolom pada visualisasi tabel.

Predictive Analysis juga dilakukan pada visualisasi mengenai rekapitulasi penelitian dosen dengan menggunakan line chart. Gambar 14 merupakan dashboard yang berisi Forecast anggaran dana rekapitulasi penelitian dosen hingga tahun 2021. Forecast dibuat berdasarkan dana anggaran yang dikeluarkan selama 4 tahun yang dimulai dari tahun 2015. Kolom yang menjadi sumber data dari Forecasting adalah kolom tahun dan jumlah dana pada tabel gabungan. 


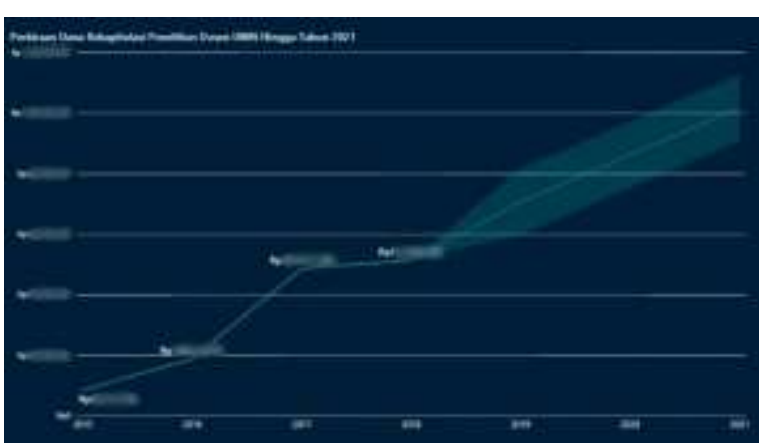

Gambar 14. Forecast Rekapitulasi Penelitian Dosen

Dashboard terakhir adalah mengenai penelitian hibah dikti yang dapat dilihat pada gambar 15 .

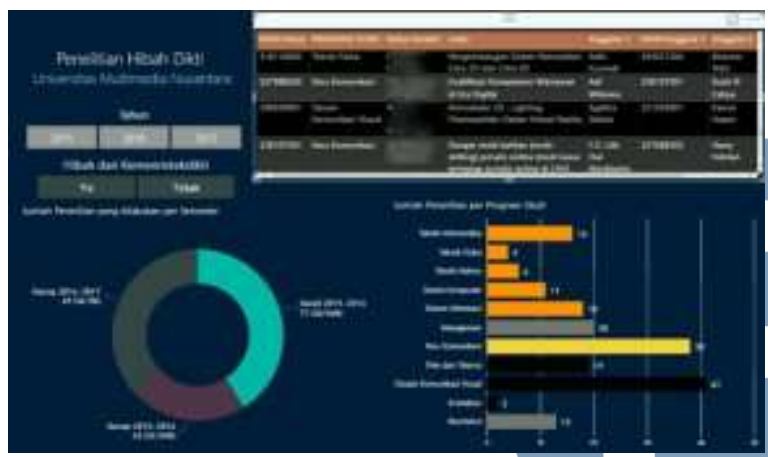

Gambar 15. Dashboard Penelitian Hibah Dikti

Komponen diagram dan jenis visualisasi yang digunakan dalam dashboard penelitian dikti adalah sebagai berikut:

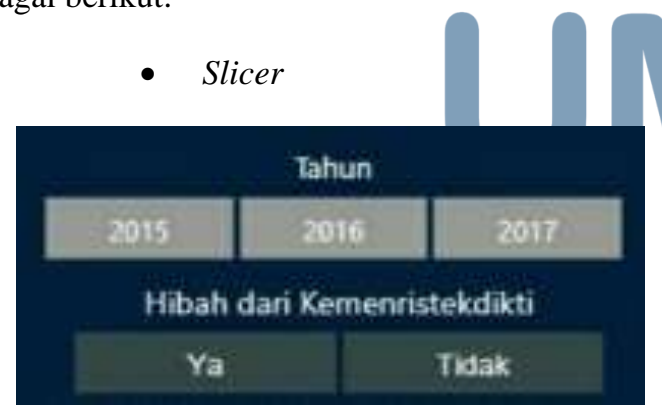

Gambar 16. Slicer dalam Dashboard Call For Paper

Penelitian dapat dilihat berdasarkan status yang dimiliki laporan penelitian dan status kontrak penelitian. Kolom status penelitian dan kontrak pennelitian adalah kolom yang digunakan sebagai dasar informasi dari slicer.

\section{- $\quad$ Stacked-bar Chart}

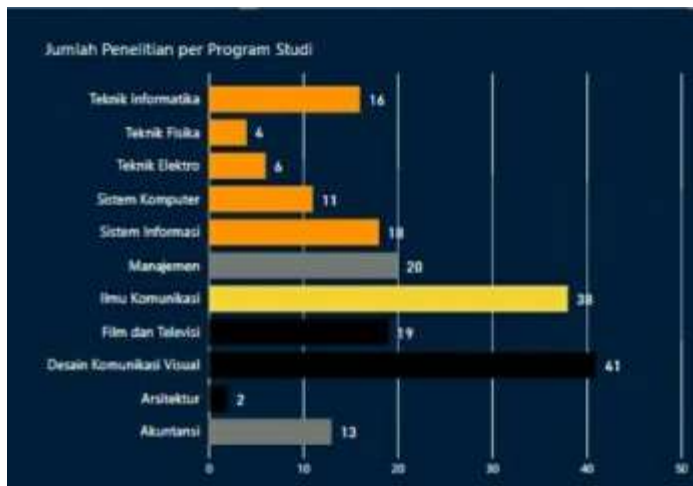

Gambar 17. Stacked-bar Chart dalam Dashboard Call For Paper

Informasi yang disajikan stacked bar chart adalah jumlah penelitian yang dilakukan oleh universitas dalam periode tertentu.

\section{- Donut chart}

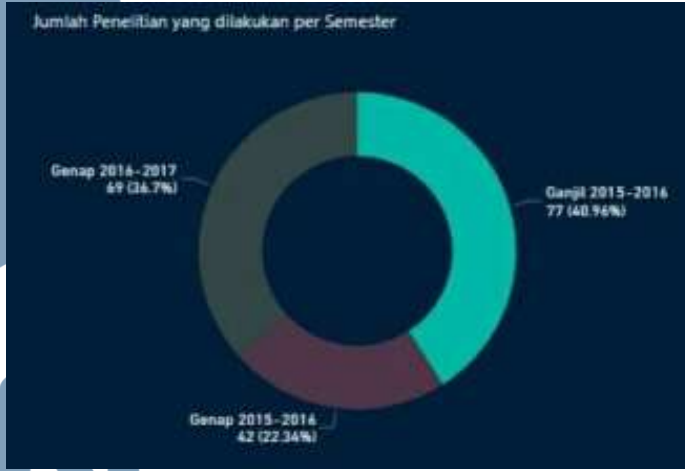

Gambar 18. Stacked-bar Chart dalam Dashboard Call For Paper

Donut chart menampilkan banyak penelitian yang terbagi sesuai semester ganjil dan genap yang sudah berjalan yang dilengkapi dengan tahun.

- Table

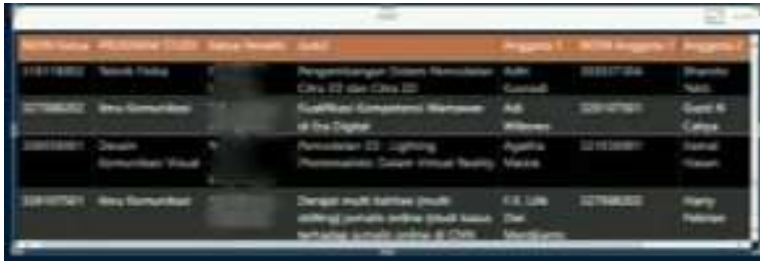

Gambar 19. Table dalam Dashboard Call For Paper

Informasi yang terdapat pada tabel adalah NIDN dan nama dari ketua, 
anggota 1 dan anggota 2, serta program studi dan judul dari penelitian yang dilakukan.

\section{SIMPULAN}

Universitas Multimedia Nusantara merupakan salah satu universitas swasta di Indonesia yang turut memberikan sumbangsih kepada negara, salah satunya berupa penelitian yang terus dilakukan sesuai dengan ketentuan yang ada. Sebagai koordinator yang memiliki tugas untuk mengelola pendanaan dan perijinan peneitian dalam universitas, LPPM harus meneliti berbagai informasi yang tersedia.

Data mengenai pendanaan penelitian semakin bertambah banyak seiring berjalannya waktu, hal ini membuat data menjadi semakin sulit untuk diolah dan dilihat. Melalui visualisasi data, informasi yang ada dapat dimengerti dalam waktu yang lebih singkat daripada melihat seluruh informasi dalam bentuk tabel dan lebih mudah karena informasi yang ada dikemas dalam berbagai diagram dengan warna dan bentuk yang menarik. Informasi yang mudah dilihat membuat proses pengambilan keputusan menjadi lebih mudah.

\section{UCAPAN TERIMA KASIH}

Terima kasih kepada admin LPPM yang sedang bertugas atas jasanya menyediakan data yang dibutuhkan selama proses pembuatan visualisasi data penelitian universitas serta Head of Research yang telah membimbing dan memberikan rekomendasi fitur yang ada dalam report.

[1] Breul, J. D. (2017). Cyber Society, Big data, and Evaluation: Comparative Policy Evaluation. Transaction Publishers.

[2] Dunlop, N. (2015). Beginning Big data with Power BI and Excel 2013: Big data Processing and Analysis Using PowerBI in Excel 2013. Apress.

[3] Adam Jorgensen, J. R.-J. (2014). Microsoft Big data Solutions. John Wiley \& Sons.

[4] Schmarzo, B. (2013). Big data: Understanding How Data Powers Big Business. John Wiley \& Sons.

[5] Haataja, T. (2016, 11 3). Sales Forecasting in Small and Medium-Sized Enterprises. Sales Forecasting in Small and Medium-Sized Enterprises.

[6] Raghavendra Raj, S. H. (2016). Business Intelligence Solution for an SME: A Case Study. 8th International Conference on Knowledge Management and Information Sharing.

[7] Miller, J. D. (2017). Big data Visualization. Packt Publishing.

[8] Brijs, B. (2013). Business Analysis for Business Intelligence. Auerbach Publications.
[9] Michael Diamond, A. M. (2017). Data visualization: an exploratory study into the software tools used by businesses. Journal of Instructional Pedagogies .

[10] Meza Silvana, R. A. (2017). Pengembangan Model Business Intelligence Manajemen Rumah Sakit untuk Peningkatan Mutu Pelayanan. Jurnal Edukasi dan Penelitian Informatika (JEPIN).

[11] Larose, D. T. (2015). Data Mining and Predictive Analytics. John Wiley \& Sons.

[12] Dr. F. A. Gunawan, D. W. (2015). Risk Based Behavioral Safety. Gramedia Pustaka Utama. 